\title{
Characterisation of non-pigmented species of the genus Prevotella by polyacrylamide gel electrophoresis
}

\author{
R. YOUSEFI-MASHOUF, A. ELEY and B. I. DUERDEN*
}

Department of Experimental and Clinical Microbiology, University of Sheffield Medical School, Sheffield S10 $2 R X$

\begin{abstract}
Summary. Gram-negative anaerobic bacilli previously known as the melaninogenicus-oralis group of Bacteroides have been assigned to a new genus, Prevotella. The non-pigmented members of this genus share several general characteristics and cannot be readily distinguished by routine tests. A polyacrylamide slab gel electrophoresis procedure, with visual analysis of protein patterns, was used to compare cellular protein patterns from clinical isolates with those from collection (reference) strains. Reference strains of $P$. oralis, $P$. veroralis, P. buccalis, P. oris, P. buccae, P. zoogleoformans, P. bivia, P. disiens, P. oulora, B. (P.) capillus and $B$. $(P$.) pentosaceus, and 91 non-pigmented isolates from patients with adult periodontal disease were examined by conventional biochemical tests, gas-liquid chromatography (GLC) and enzyme tests, and whole-cell protein profiles were obtained by SDS-PAGE. There was close correlation between patterns of results in biochemical and GLC tests and the SDSPAGE profiles, and the species were readily distinguished in SDS-PAGE. The periodontal isolates were assigned to 10 groups by conventional test reaction patterns and nine groups by SDS-PAGE; the profiles of 79 isolates corresponded to those of seven species reference strains. By SDS-PAGE, clinical isolates of $P$. buccae ( 42 isolates) and $P$. oralis (eight isolates) showed good similarity with reference strains. However, for $P$. veroralis $(15), P$. oris (7), $P$. bivia (4), P. zoogleoformans (2) and P. buccalis (1), clinical isolates showed some minor variations from reference strains. Twelve isolates remained undesignated in SDS-PAGE analysis. Variant SDS-PAGE profiles divided clinical isolates of $P$. buccae into two subgroups and those of $P$. veroralis into five subgroups.
\end{abstract}

\section{Introduction}

Small gram-negative obligately anaerobic bacilli of the genus Prevotella (Bacteroides of the melaninogenicus-oralis group) are important members of the normal flora of the mouth and significant causes of periodontal diseases ${ }^{1-4}$ and other infections, particularly of the urogenital tract, the head and neck, and the lungs. ${ }^{4-7}$

In recent years, the genus Bacteroides has undergone major taxonomic revision and several species have been given separate genus status. ${ }^{2,8}$ It has been proposed that the genus Bacteroides be restricted to $B$. fragilis (the type species) and closely related organisms. ${ }^{8}$ However, the position of the moderately saccharolytic, predominantly oral Bacteroides spp. (B. melaninogenicus, $B$. oralis and related species) remained unresolved. ${ }^{2}$ These species share several

Received 23 Aug. 1991; accepted 11 Sept. 1991

* Present address: Department of Medical Microbiology and Public Health Laboratory, University of Wales College of Medicine, Heath Park, Cardiff CF4 4XN. general characteristics and form a phenotypically and phylogenetically coherent group that differs significantly from the emended description of the genus Bacteroides. ${ }^{2}$ These species have now been assigned to a new genus Prevotella. ${ }^{2}$ The black-pigmented members of Prevotella are well known, but the non-pigmented species have received less attention. Most of these nonpigmented species have been described only recently and are still generally reported as either $B$. $(P$.) oralis or $B$. (P.) ruminicola. So far, little information is available on their characteristics and their role in human disease.

Several authors have reported the use of SDSPAGE of soluble cellular proteins to distinguish species or to determine the similarity between isolates of bacteroides. ${ }^{9,10}$

In the present study, collection (reference) strains of Prevotella, and non-pigmented clinical isolates from patients with periodontal disease were examined. They had been characterised by biochemical, gasliquid chromatography (GLC) and enzyme tests and the results of these tests were compared with the patterns obtained by SDS-PAGE of whole-cell proteins. 
Table I. Collection strains studied

\begin{tabular}{lll}
\hline Species & Designation & Source \\
\hline$P$. oralis & NCTC 11459 & Periodontal pocket \\
$P$. veroralis & ATCC 33779 & Oral cavity \\
$P$. veroralis & $83-457 \mathrm{~F}^{*}$ & \\
$P$. buccalis & ATCC 35310 & Dental plaque \\
$P$. bivia & VPI 6622 & Endometrium \\
$P$. bivia & VPI $5540 \dagger$ & \\
$P$. disiens & NCTC 11157 & Bartholin abscess \\
$P$. oulora & NCTC 11871 & Subgingival plaque \\
$P$. buccae & ATCC 33574 & Gingival crevice \\
$P$. buccae & $83-617^{*}$ & \\
$P$. oris & ATCC 33573 & Gingival crevice \\
$P$. oris & $86-20 I D D *$ & \\
$P$. zoogleoformans & ATCC 33285 & Oral cavity \\
$B .(P$.$) capillus \ddagger$ & ATCC 33690 & Periodontal pocket \\
$B .(P$.$) pentosaceus \ddagger$ & NP 333 & Dental plaque \\
$B .(P$.$) pentosaceus \ddagger$ & WPH 61 & Dental plaque \\
\end{tabular}

* Donated by Dr S. M. Finegold, V.A. Wadsworth Medical Centre, California.

$\dagger$ Donated by Dr E. M. Barnes, A.F.R.C. Food Research Institute, Colney Lane, Norwich.

$\ddagger$ These species have been suggested to be synonymous with P. buccae. ${ }^{24}$

\section{Materials and methods}

\section{Bacterial strains}

The strains studied comprised 16 reference strains from collections (table I) and 91 clinical isolates from 21 adult patients with periodontal disease. All were checked for purity on BM agar, ${ }^{11}$ incubated anaerobically $\left(\mathrm{H}_{2} 10 \%, \mathrm{CO}_{2} 10 \%, \mathrm{~N}_{2} 80 \%\right)$ at $37^{\circ} \mathrm{C}$ for $72 \mathrm{~h}$ and on blood agar incubated aerobically with $\mathrm{CO}_{2} 10 \%$; growth from anaerobic cultures was then suspended in a freezing medium of Nutrient Broth No. 2 (Oxoid) with inactivated horse serum (Wellcome) $10 \%$ and glucose $1 \%$ and held at $-70^{\circ} \mathrm{C}$ in liquid nitrogen.

\section{Characterisation tests}

The strains were characterised and identified by a combination of biochemical reactions, antibiotic disk susceptibility and tolerance tests, fluorescence under UV light, GLC analysis and tests for enzyme activity as previously described ${ }^{12}$ and summarised briefly below.

Biochemical tests. Strains were tested for production of indole; hydrolysis of aesculin and starch; production of acid from glucose, lactose, sucrose, rhamnose, trehalose, xylose, maltose, arabinose, cellobiose, salicin, inulin and xylan; ${ }^{12,13}$ hydrolysis of hippurate with diagnostic tablets; $;^{14}$ and hydrolysis of indoxyl acetate by the method of Popovic-Uroic et al. ${ }^{15}$

GLC analysis. Volatile (VFA) and non-volatile (NVFA) fatty acid end-products of metabolism were determined after growth in Fastidious Anaerobe Broth (FAB) (Lab M, Bury, Lancs) for 4-5 days by a modification of the method of Holdeman et al. ${ }^{16}$
Enzyme activities. The production of $\beta$-xylosidase, $\beta$-glucuronidase, $\alpha$ - and $\beta$-glucosidase, $\alpha$ - and $\beta$ galactosidase, $\alpha$-fucosidase, $\beta$ - $\mathrm{N}$-acetylglucosaminidase, and $\alpha$-mannosidase was tested with Rosco Diagnostic tablets (Lab M). ${ }^{14}$

\section{$S D S-P A G E$}

SDS-PAGE was performed by a modification of the method of Laemmli. ${ }^{17}$

Preparation of protein samples. Strains were grown on BM agar $^{11}$ for 2-3 days in an anaerobic cabinet (Don Whitley Scientific Ltd, Shipley, W. Yorkshire) in an atmosphere of $\mathrm{H}_{2} 10 \%, \mathrm{CO}_{2} 10 \%, \mathrm{~N}_{2} 80 \%$. Growth was harvested and the weight of the wet pellets was standardised to between 100 and $150 \mathrm{mg}$. The pellets were washed three times in $1 \mathrm{ml}$ of sterile distilled water and suspended in $150 \mu \mathrm{l}$ of double strength lysis buffer containing SDS $6 \% \mathrm{w} / \mathrm{v}$, glycerol $20 \% \mathrm{v} / \mathrm{v}, 2$-mercaptophenol $10 \% \mathrm{v} / \mathrm{v}, 0 \cdot 125 \mathrm{M}$ Tris$\mathrm{HCl}(\mathrm{pH} \mathrm{6.8)}$ and bromophenol blue $0.005 \% \mathrm{w} / \mathrm{v}$. The suspensions were boiled in a water bath at $100^{\circ} \mathrm{C}$ for $5 \mathrm{~min}$; $150 \mu \mathrm{l}$ of sterile distilled water was added and the samples were boiled again for $5 \mathrm{~min}$. Lysates were centrifuged and the supernates were tested.

Loading and running the gels. The separating gel contained $(\mathrm{w} / \mathrm{v})$ polyacrylamide $10 \%$, SDS $0 \cdot 1 \%$, ammonium persulphate (APS) $0.06 \%$, TEMED $0.1 \%$ and $0.375 \mathrm{M}$ Tris- $\mathrm{HCl}(\mathrm{pH} 8 \cdot 8)$. The stacking gel contained $(\mathrm{w} / \mathrm{v})$ polyacrylamide $5 \%$, SDS $0 \cdot 1 \%$, APS $0.05 \%$, TEMED $0 \cdot 1 \%$ and $0.125 \mathrm{M}$ Tris- $\mathrm{HCl}(\mathrm{pH} 6 \cdot 8)$. The apparatus was a vertical electrophoresis tank (model V16; BRL, Bethesda, MD, USA). The gels were $1.5 \mathrm{~mm}$ thick with 17 wells in each; $10 \mu \mathrm{l}$ of sample was loaded into each well with protein mol. wt markers (29-205 kDa; Sigma) in one well of each gel. Electrophoresis was at constant $60 \mathrm{~V}$ until the tracking dye reached the bottom of the separating gel (approx. $12 \mathrm{~h}$ ).

Staining. Gels were stained for $3 \mathrm{~h}$ in Coomassie Brilliant Blue (CBB) R-250 (CBB 2.5 g, methanol $500 \mathrm{ml}$, trichloroacetic acid $100 \mathrm{~g}$, distilled water $400 \mathrm{ml}$ ), destained with several changes of methanol $20 \% \mathrm{v} / \mathrm{v}$ and glacial acetic acid $7.5 \% \mathrm{v} / \mathrm{v}$ in water, and photographed through an orange filter (23 $\mathrm{A})$.

\section{Results}

The gels and photographs were examined with the naked eye and strains were separated into similar groups, based on the number and position of protein bands (figs. 1-8); at least one reference strain of another Prevotella sp. was included as a control in each gel that was used primarily to show similarities between strains of a single species or group.

Protein profiles of 91 oral non-pigmented clinical isolates previously assigned to 10 distinct groups by the results of biochemical, GLC and enzyme tests ${ }^{12}$ (table II) were compared with profiles of the reference 
Table II. Summary of the biochemical, GLC and enzyme results of clinical isolates

\begin{tabular}{|c|c|c|c|c|c|c|c|c|c|c|}
\hline \multirow{2}{*}{$\begin{array}{l}\text { Test } \\
\text { Dye tolerance }\end{array}$} & \multicolumn{10}{|c|}{ Patterns of results } \\
\hline & & & & & & & & & & \\
\hline Victoria blue $4 \mathrm{R}$ & + & I & I & $+/ \mathbf{I}$ & + & $+/ \mathrm{I}$ & + & I & + & + \\
\hline Indole production & - & - & - & - & - & - & - & - & - & - \\
\hline \multicolumn{11}{|l|}{ Hydrolysis of: } \\
\hline aesculin & + & + & + & + & + & + & + & $\mathbf{w}$ & - & - \\
\hline hippurate & - & - & - & - & - & - & + & - & + & - \\
\hline starch & + & + & + & + & + & $+1-$ & w & - & + & $v$ \\
\hline indoxyl acetate & + & + & + & + & + & $\mathrm{v}$ & $\mathbf{v}$ & + & + & w \\
\hline Fluorescence & - & - & - & $+^{p}$ & - & $t^{r}$ & - & - & $t^{r}$ & $t^{r}$ \\
\hline Pigmentation & - & - & - & - & - & $\mathbf{v}$ & - & - & - & - \\
\hline \multicolumn{11}{|l|}{ Acid produced from: } \\
\hline lactose & + & + & + & + & + & + & + & + & + & $\mathrm{w} /+$ \\
\hline sucrose & + & + & + & + & + & + & + & + & - & w/t \\
\hline rhamnose & $+1-$ & - & - & - & - & - & - & - & - & - \\
\hline trehalose & - & - & - & - & - & - & - & - & - & - \\
\hline xylose & + & + & + & + & - & - & - & - & - & - \\
\hline arabinose & + & + & + & + & - & - & - & - & - & - \\
\hline cellobiose & + & + & + & + & + & $+1-$ & + & - & - & - \\
\hline salicin & + & + & + & + & $+1-$ & - & - & - & - & - \\
\hline inulin & $+1-$ & + & + & - & w & $+1-$ & w & - & - & - \\
\hline xylan & $+1-$ & - & - & - & - & $\mathrm{v}$ & - & - & - & - \\
\hline \multicolumn{11}{|l|}{ End products (GLC): } \\
\hline acetic & ++ & + & ++ & ++ & ++ & ++ & ++ & ++ & ++ & ++ \\
\hline propionic & $\operatorname{tr}$ & ++ & - & + & - & - & - & + & - & - \\
\hline iso-butyric & tr & ++ & ++ & - & - & $+/-$ & + & - & + & $+/ \mathrm{tr}$ \\
\hline butyric & - & - & - & $\operatorname{tr}$ & $\operatorname{tr}$ & - & - & $\operatorname{tr}$ & - & - \\
\hline iso-valeric & ++ & ++ & ++ & $\operatorname{tr}$ & $\operatorname{tr}$ & $+/-$ & ++ & + & ++ & ++ \\
\hline pyruvic & - & - & - & - & - & $\operatorname{tr} /-$ & $\operatorname{tr}$ & - & - & - \\
\hline lactic. & $\operatorname{tr}$ & $\operatorname{tr}$ & + & $\operatorname{tr}$ & + & + & + & + & + & + \\
\hline succinic & ++ & ++ & ++ & ++ & ++ & ++ & ++ & ++ & ++ & ++ \\
\hline phenylacetic & - & + & - & - & $\operatorname{tr}$ & - & - & - & - & - \\
\hline \multicolumn{11}{|l|}{ Enzyme production: } \\
\hline$\beta$-xylosidase & + & + & + & $-/+$ & $+1-$ & - & - & - & - & - \\
\hline$\beta$-glucuronidase & - & + & - & + & - & - & - & - & - & - \\
\hline$\beta$-glucosidase & + & + & + & + & + & + & + & - & - & - \\
\hline$\alpha$-galactosidase & + & + & + & + & + & + & + & - & $+1-$ & + \\
\hline$\beta$-galactosidase & + & + & + & + & + & + & + & - & - & $+1-$ \\
\hline$\alpha$-fucosidase & - & + & + & + & + & + & + & + & + & + \\
\hline$\beta$-NAGase & - & + & + & + & + & + & + & + & + & + \\
\hline$\alpha$-mannosidase & - & + & + & $+1-$ & $-1+$ & + & + & $\mathbf{w}$ & $+/-$ & $+/-$ \\
\hline Numbers of isolates & 42 & 2 & 4 & 7 & 8 & 15 & 1 & 1 & 4 & 7 \\
\hline Groups & A & B & $\mathrm{C}$ & D & $\mathrm{E}$ & $\mathrm{F}$ & G & $\mathrm{H}$ & I & $\mathbf{J}$ \\
\hline
\end{tabular}

I, inhibition; + , growth,+ , positive reaction; - , negative reaction $;+/-$, most reactions positive; $-/+$, most reactions negative; w, weak reaction; $v$, variable reaction; $p$, pale fluorescence; $r$, red fluorescence; ++ , major production; + , minor; tr, trace; - , none produced; $\beta$-NAGase, $\beta$-N-acetyl-glucosaminidase.

strains whose test results are shown in table III. Protein profiles for the majority of isolates were similar to those of seven reference species and were allocated to nine groups:

Group I-42 isolates (group A, table II) biochemically identified as $P$. buccae (column 1 , table III) gave very similar SDS-PAGE profiles closely corresponding to that of the reference strain $P$. buccae ATCC 33574; one collection strain (P. buccae 83-617) and six clinical isolates lacked a major protein band of c. $116 \mathrm{kDa}$, and formed the minor subgroup Ib (fig. 1). $P$. oris ATCC 33573 (track 2) was included for comparative purposes and differed from $P$. buccae ATCC 33574 and 83-617 in the regions of c. $25-30 \mathrm{kDa}$ and other minor bands (fig. 1).

Group II-six isolates (group B and C, table II) biochemically identified as $P$. zoogleoformans (column 2 , table III) gave two distinct subgroups by SDS-
PAGE profiles; subgroup IIa (two isolates; group B, table II) differed from the $P$. zoogleoformans reference strain ATCC 33285 only by the presence of two protein bands in the mol. wt regions $c .27$ and $37 \mathrm{kDa}$, but subgroup IIb (four isolates; group C, table II) differed in bands at $48,66,97.4$ and $116 \mathrm{kDa}$; thus, subgroup IIb remained in an undesignated SDSPAGE group (fig. 2). P. oris ATCC 33573 (track 2). B. $(P$.) pentosaceus NP 333 and WPH 61 (tracks 3 and 4) and $P$. buccae ATCC 33574 (track 5) were applied as reference controls and differed from $P$. zoogleoformans in several major and minor bands (fig. 2). These strains were very similar in conventional biochemical tests.

Group III-seven isolates (group D, table II) biochemically identified as $P$. oris (column 4 , table III) had similar GLC patterns in spite of their variation in biochemical tests. They differed from the $P$. oris reference strain ATCC 33573 by SDS-PAGE profile in 
Table III. Summary of the biochemical, GLC and enzyme results of the reference strains

\begin{tabular}{|c|c|c|c|c|c|c|c|c|c|c|}
\hline \multirow{2}{*}{ Test } & \multicolumn{10}{|c|}{ Results obtained with strains } \\
\hline & 1 & 2 & 3 & 4 & 5 & 6 & 7 & 8 & 9 & 10 \\
\hline \multicolumn{11}{|l|}{ Dye tolerance } \\
\hline Victoria blue $4 \mathrm{R}$ & + & I & + & I & + & + & + & I & + & + \\
\hline Indole production & - & - & - & - & - & - & - & - & - & - \\
\hline \multicolumn{11}{|l|}{ Hydrolysis of: } \\
\hline aesculin & + & + & + & + & + & + & + & - & - & - \\
\hline hippurate & - & - & - & - & - & - & + & - & + & + \\
\hline starch & + & - & + & + & $\mathbf{w}$ & $\mathbf{v}$ & - & - & + & w \\
\hline indoxyl acetate & + & + & + & + & w & w & $\mathrm{v}$ & + & + & + \\
\hline Fluorescence & - & - & - & - & - & $+^{p}$ & - & - & $t^{r}$ & $+^{r}$ \\
\hline Pigmentation & - & - & - & - & - & - & - & - & - & - \\
\hline \multicolumn{11}{|l|}{ Acid produced from: } \\
\hline lactose & + & + & + & + & + & + & + & + & + & - \\
\hline sucrose & + & + & + & + & + & + & + & + & - & - \\
\hline rhamnose & $+1-$ & - & - & - & - & - & - & - & - & - \\
\hline trehalose & - & - & - & - & - & - & - & - & - & - \\
\hline xylose & + & + & + & + & - & - & - & - & - & - \\
\hline arabinose & + & + & + & + & - & - & - & - & - & - \\
\hline cellobiose & + & + & + & + & + & + & + & - & - & - \\
\hline salicin & + & + & + & + & + & - & - & - & - & - \\
\hline inulin & + & + & + & + & $\mathbf{w}$ & + & $\mathrm{v}$ & - & - & - \\
\hline xylan & + & - & - & - & - & $\mathbf{w}$ & - & - & - & - \\
\hline \multicolumn{11}{|c|}{ End products (GLC): } \\
\hline acetic & ++ & + & + & ++ & ++ & ++ & ++ & ++ & ++ & ++ \\
\hline propionic & $\operatorname{tr}$ & ++ & ++ & + & - & - & - & ++ & - & - \\
\hline iso-butyric & $\operatorname{tr}$ & ++ & ++ & - & - & $\operatorname{tr}$ & + & - & ++ & $\operatorname{tr}$ \\
\hline butyric & - & $\operatorname{tr}$ & - & - & $\mathrm{tr}$ & - & - & $\operatorname{tr}$ & $\operatorname{tr}$ & $\mathrm{tr}$ \\
\hline iso-valeric & + & ++ & ++ & + & $\operatorname{tr}$ & ++ & ++ & $\operatorname{tr}$ & ++ & + \\
\hline pyruvic & - & - & - & - & - & $\operatorname{tr} /-$ & $\operatorname{tr}$ & - & - & - \\
\hline lactic & $\operatorname{tr}$ & $\operatorname{tr}$ & $\operatorname{tr}$ & $\operatorname{tr}$ & + & + & + & + & + & + \\
\hline succinic & ++ & ++ & ++ & ++ & ++ & ++ & ++ & ++ & ++ & ++ \\
\hline phenylacetic & - & + & + & $+1-$ & $\operatorname{tr}$ & - & - & - & - & - \\
\hline \multicolumn{11}{|l|}{ Enzyme production: } \\
\hline$\beta$-xylosidase & + & - & - & - & w & - & - & - & - & - \\
\hline$\beta$-glucuronidase & - & + & - & + & - & - & - & - & - & - \\
\hline$\beta$-glucosidase & + & + & + & + & + & + & + & - & - & - \\
\hline$\alpha$-galactosidase & + & + & + & + & + & + & + & + & - & + \\
\hline$\beta$-galactosidase & + & + & + & + & + & + & + & + & $\mathrm{v}$ & - \\
\hline$\alpha$-fucosidase & - & + & + & + & + & + & + & - & + & - \\
\hline$\beta$-NAGase & - & + & + & + & + & + & + & w & w & - \\
\hline$\alpha$-mannosidase & - & $\mathrm{v}$ & - & + & - & + & + & + & + & $\mathrm{v}$ \\
\hline
\end{tabular}

See footnote to table II; $1, P$. buccae ATCC 33574, 83-617 and B. (P.) capillus ATCC 33690; 2, P. zoogleoformans ATCC 33285; $3, B$. ( $P$.) pentosaceus NP 333 and WPH $61 ; 4, P$. oris ATCC 33573 and 86-20IDD; 5 , P. oralis NCTC 11459; 6, P. veroralis ATCC 33779 and 83-457F; $7, P$. buccalis ATCC $35310 ; 8, P$. oulora NCTC $11871 ; 9, P$. bivia VPI 5540 and VPI 6622; 10, P. disiens NCTC 11157.

protein bands in the mol. wt regions $c .18,25,29$ and $63 \mathrm{kDa}$ (fig. 3). B. (P.) pentosaceus NP 333 and $P$. buccae ATCC 33574 (tracks 2 and 3) were applied for comparative purposes and differed from $P$. oris 8620IDD and ATCC 33573 (tracks 3 and 4) in several proteins bands, particularly in the regions $29-66 \mathrm{kDa}$ (fig. 3).

Group $I V$-eight isolates (group E, table II) identified as $P$. oralis (column 5 , table III), but with some variation in conventional tests, gave SDS-PAGE profiles identical to that of the $P$. oralis reference strain NCTC 11459; one isolate showed slight differences with a single protein band in the mol. wt region $c .87 \mathrm{kDa}$ (fig. 4). P. veroralis ATCC 33779 and $P$. buccalis ATCC 35310 (tracks 2 and 3) were used as reference controls and differed from $P$. oralis NCTC 11459 (track 4) in a few protein bands, particularly in the regions $c .25$ and $116 \mathrm{kDa}$ (fig. 4).

Group $V$-strains in this biochemically hetero- geneous group of 15 isolates (group F, table II) gave an identical pattern in GLC and enzyme tests and were similar to $P$. veroralis (column 6, table III). They were separated into five subgroups ( $a, b, c, d$ and e) in SDSPAGE profiles, which differed from that of the $P$. veroralis reference strain ATCC 33779 in protein bands of $c .25,27,31,65,67$ and $116 \mathrm{kDa}$ (fig. 5).

Groups VI and VII-each comprised a single isolate with distinct characteristics (groups $\mathrm{G}$ and $\mathrm{H}$, table II). Group VI showed some variation from $P$. buccalis ATCC 35310 (column 7, table III) in conventional test reaction patterns and SDS-PAGE profiles (fig. 6). Group VII was biochemically similar to $P$. oulora NCTC 11871 (column 8, table III), but there were more differences in their SDS-PAGE profiles than in other tests; therefore, this single clinical isolate remained in an undesignated SDS-PAGE group (fig. 6).

Group VIII-four isolates (group I, table II) identified as $P$. bivia (column 9, table III) gave similar 


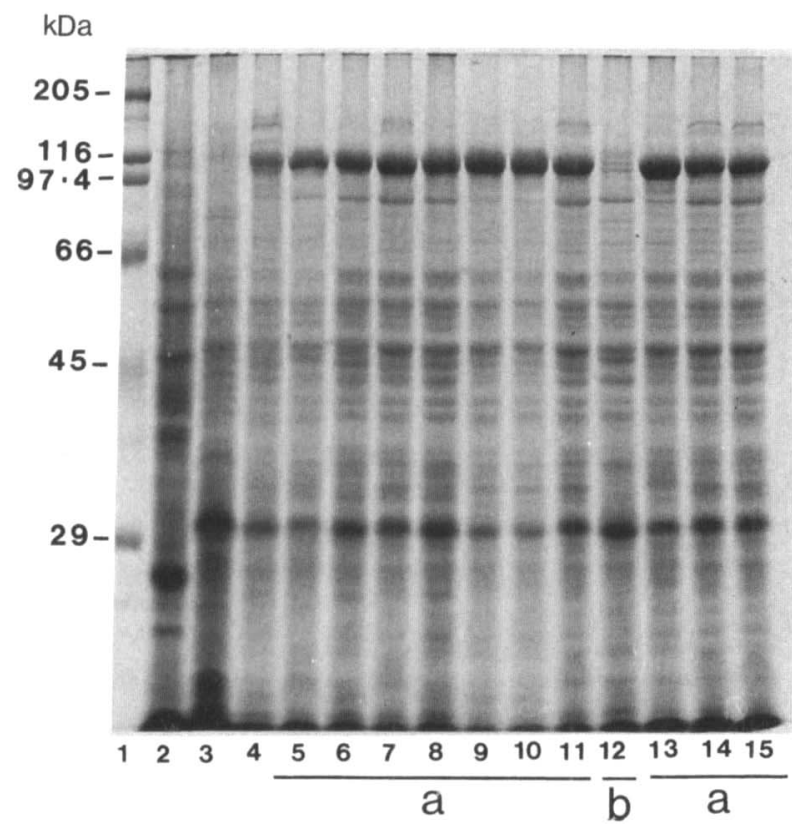

Fig. 1. SDS-PAGE profiles of clinical isolates identified as $P$. buccae (group I). Track 1, mol. wt markers; 2, P. oris ATCC 33573; 3 and 4, P. buccae 83-617 and ATCC 33574; 5-11 and 13-15, examples of clinical isolates subgroup $a ; 12$, example of subgroup $b$.

SDS-PAGE profiles except for the absence of a few bands at $c .26,37$ and $17 \mathrm{kDa}$ (fig. 7). P. disiens NCTC 11157 (track 2) was applied as a reference control and differed from P. bivia VPI 6622 and VPI 5540 (tracks 3 and 4 ) in several protein bands, particularly in the regions $c$. 29-66 and $116 \mathrm{kDa}$ (fig. 7).

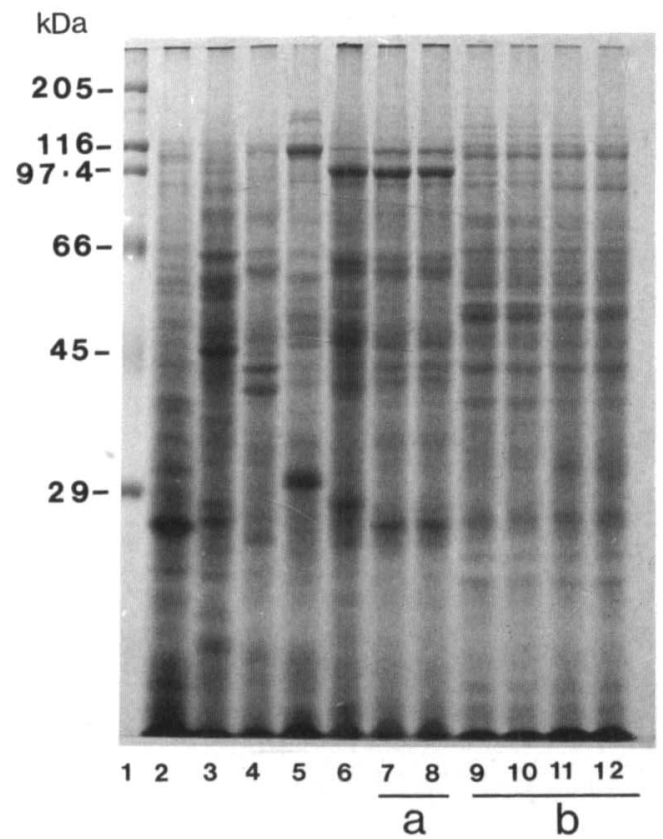

Fig. 2. SDS-PAGE profiles of clinical isolates identified as $P$. zoogleoformans (group II). Track 1, mol. wt markers; 2, P. oris ATCC $33573 ; 3-4, B .(P$.) pentosaceus WPH 61 , NP $333 ; 5$, P. buccae ATCC 33574; 6, P. zoogleoformans ATCC 33285; 7 and 8 , clinical isolates subgroup $a ; 9-12$, clinical isolates subgroup $b$ (undesignated SDS-PAGE group).

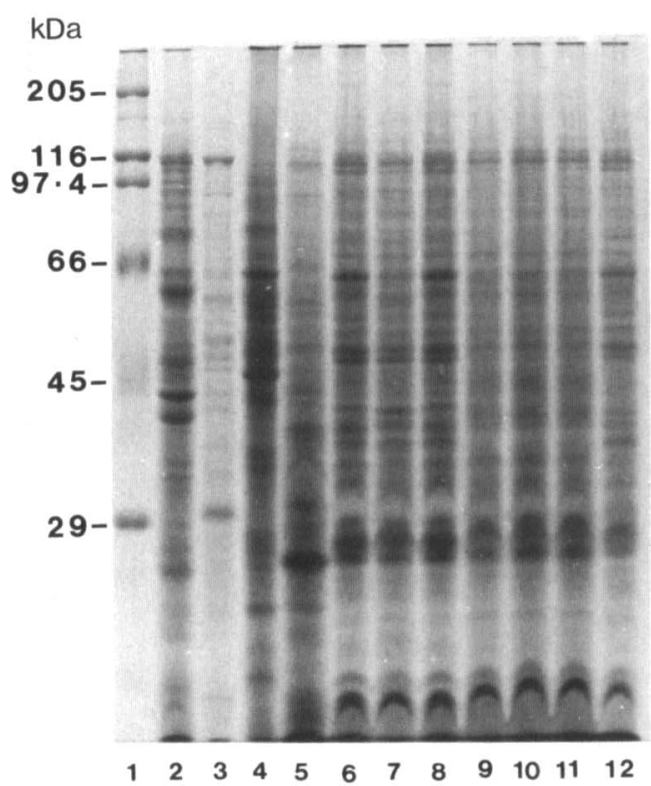

Fig. 3. SDS-PAGE protein profiles of clinical isolates identified as $P$. oris (group III). Track 1, mol. wt markers; $2, B$. (P.) pentosaceus NP $333 ; 3, P$. buccae ATCC $33574 ; 4, P$. oris $86-20$ IDD; 5 , $P$. oris ATCC $33573 ; 6-12$, clinical isolates.

Group IX -these seven isolates (group J, table II) did not correspond with any of the reference strains. They were divided into two subgroups in SDS-PAGE. The five isolates of subgroup IXa had similar patterns of results in biochemical, GLC and enzyme tests and similar SDS-PAGE profiles. The two isolates of IXb showed minor variations in biochemical and SDSPAGE profiles (fig. 8).

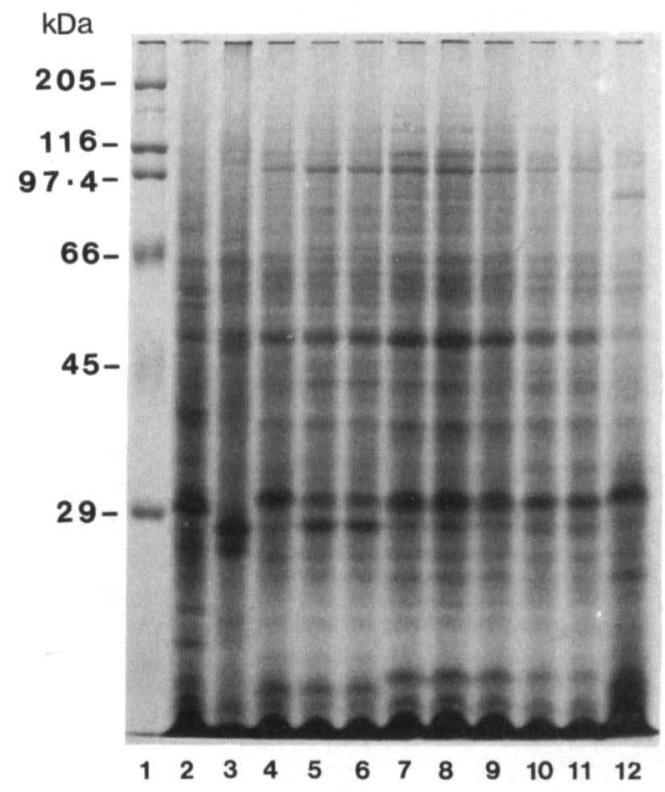

Fig. 4. SDS-PAGE profiles of clinical isolates identified as $P$. oralis (group IV). Track 1, mol. wt markers; 2, P. buccalis ATCC 35310; 3 , $P$. veroralis ATCC $33779 ; 4$, $P$. oralis NCTC $11459 ;$ 5-12, clinical isolates. 


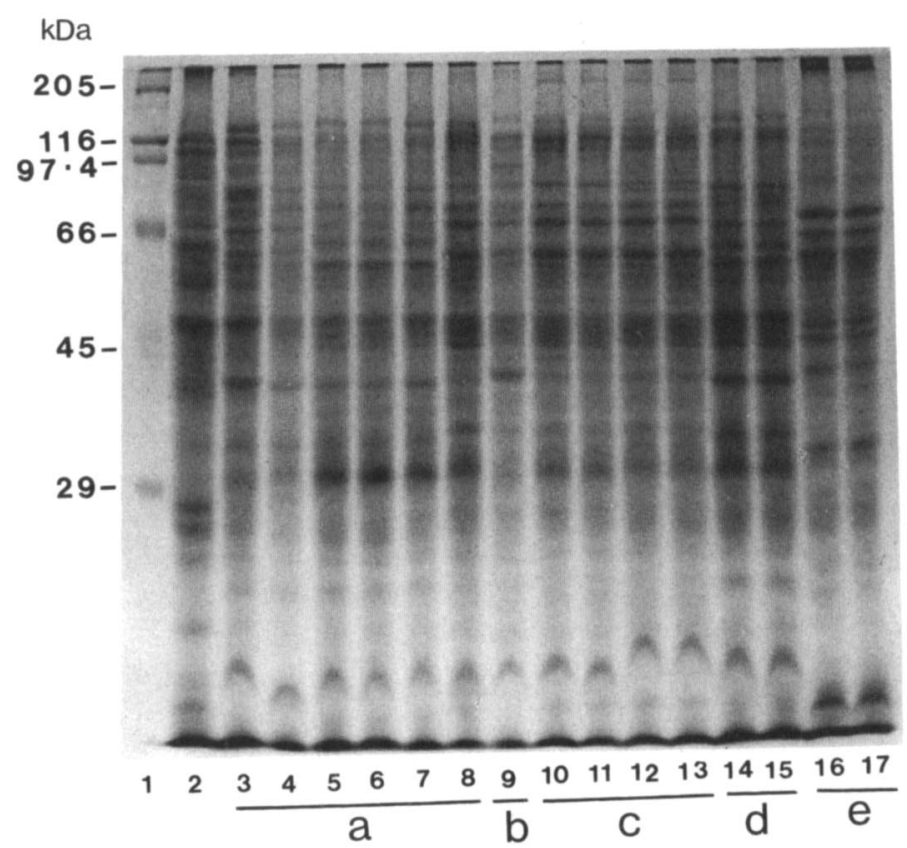

Fig. 5. SDS-PAGE profiles of clinical isolates identified as $P$. veroralis (group V). Track 1, mol. wt markers; 2 , P. veroralis ATCC $33779 ; 3-8$ clinical isolates of subgroup a; 9 , subgroup b; 10-13, subgroup c; 14 and 15, subgroup d; 16 and 17, subgroup e.

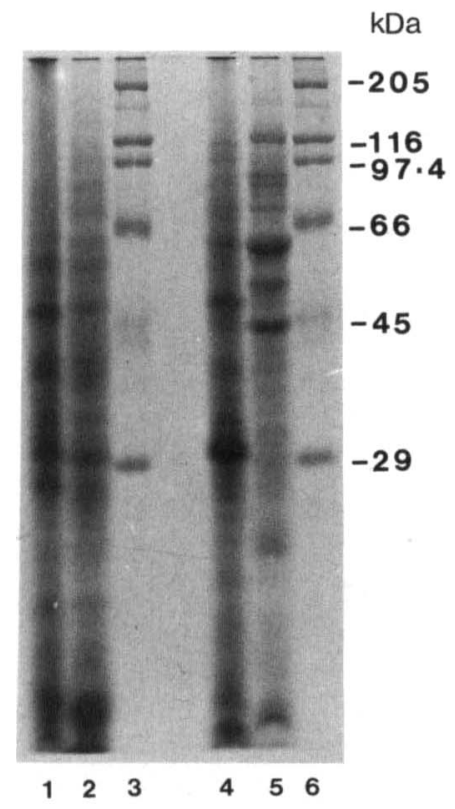

Fig. 6. SDS-PAGE profiles of clinical isolates of groups VI and VII. Tracks 3 and 6, mol. wt markers; 1 , clinical isolate (group VI); $2, P$. buccalis ATCC $35310 ; 4$, clinical isolate (undesignated SDS-PAGE group); 5, P. oulora NCTC 11871 .

\section{Discussion}

Among the recognised species of the genus Prevotella, the black-pigmented species have been well studied and classified. However, the non-pigmented species have not been so closely studied. Most of the non-pigmented species ( $P$. veroralis, $P$. oulora, $P$. buccalis and $P$. zoogleoformans) have been described

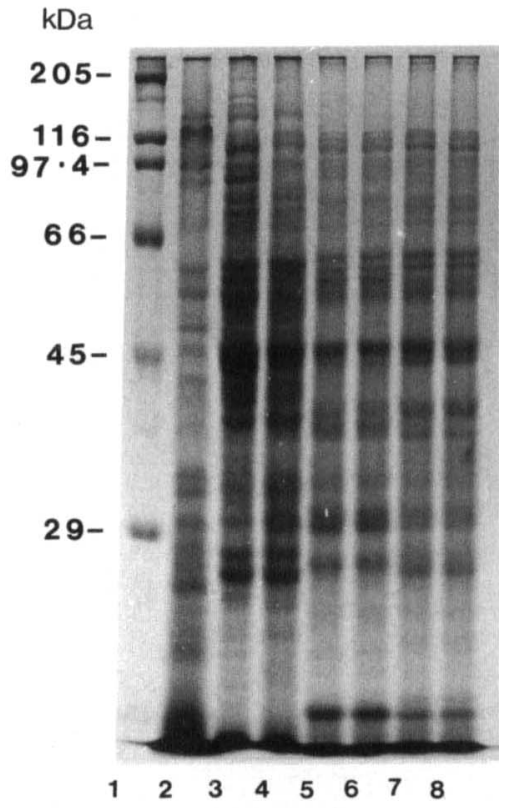

Fig. 7. SDS-PAGE profiles of clinical isolates identified as $P$. bivia. Track 1, mol. wt markers; $2, P$. disiens NCTC $11157 ; 3$ and $4, P$. bivia VPI 6622 and VPI 5540; 5-8, clinical isolates.

only recently, ${ }^{18-21}$ are generally still reported as either " $B$. ( $(P$.$) oralis" or " B$. (P.) ruminicola", and few data are available on their general characteristics and role in human disease.

In the previous study, ${ }^{12}$ each of the three analytical approaches (biochemical, GLC and enzyme tests) contributed to the identification of the species within this group. The technique of polyacrylamide slab gel 


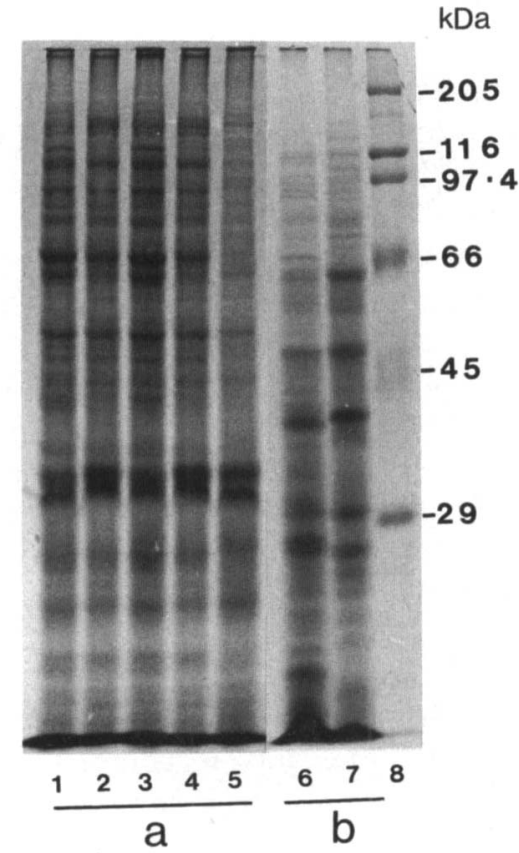

Fig. 8. SDS-PAGE profiles of group IX (undesignated spp.) 1-5, clinical isolates of subgroup a; 6 and 7 , subgroup b;8, mol. wt markers.

electrophoresis also appeared to be useful in characterisation and classification of strains within the genus Prevotella. The use of slab gels enabled resolution of proteins in a mol. wt range from $c .15-205 \mathrm{kDa}$ in a gel $14 \mathrm{~cm}$ long, and the protein profiles of the majority of the species produced discrete bands allowing good differentiation. For each strain, the profiles were reproducible in successive extractions and gels. The strains of each species gave similar overall profiles, but the profiles could differ in specific bands. Species discrimination was mainly obtained by well stained, major protein bands. The degree of resemblance of strains was assessed visually. This was adequate for strains adjacent to each other on a gel, particularly if they demonstrated identical protein patterns. The age of the culture or number of subcultures did not appear to result in a significant variation in the protein profiles. Re-analysis of the protein extracts after storage at $-20^{\circ} \mathrm{C}$ for several weeks caused the omission of some minor protein bands. The most critical factor affecting reproducibility of the gel patterns appeared to be sensitivity of the acrylamide solutions to oxygen, and it was necessary to de-gas the acrylamide solutions thoroughly before the ammonium persulphate was added.

Some groups of strains ( $P$. buccae, B. $(P$.) capillus, $P$. disiens, $P$. bivia, $P$. zoogleoformans and $B$. $(P$.) pentosaceus) were easily lysed during the process of protein extraction (the EL group), whereas others ( $P$. oralis, $P$. veroralis, $P$. buccalis, $P$. oulora and $P$. oris) were difficult to lyse (the DL group). Although $P$. zoogleoformans and $B$. (P.) pentosaceus were readily lysed, they produced a viscous and sticky protein extract. In these species the high concentration of soluble protein in the extracts caused problems with band smearing and over-staining, making the SDSPAGE patterns difficult to interpret.

In this study, the SDS-PAGE profiles of most (79) clinical isolates were similar to those of seven reference strains, and enabled species differentiation. The isolates that were provisionally classified as $P$. buccae and $P$. oralis by conventional tests, ${ }^{12}$ gave protein profiles identical with reference strains. However, isolates identified as $P$. veroralis, $P$. oris, $P$. bivia, $P$. zoogleoformans and $P$. buccalis differed from reference strains by some protein bands; 12 clinical isolates remained in three undesignated SDS-PAGE groups (IIb, VII and IXa) which may represent previously undesignated species.

$P$. buccae (group I) was the most commonly isolated of the non-pigmented Prevotella spp. from periodontal pockets, in agreement with findings of Haapasalo ${ }^{4,22}$ and Johnston et al. ${ }^{23}$ SDS-PAGE confirmed that these strains (group I) were correctly identified as $P$. buccae in the previous conventional study. ${ }^{12}$ P. buccae ATCC 33574, B. (P.) capillus ATCC 33690 and B. (P.) pentosaceus NP 333 and WPH 61 had similar biochemical properties and have recently been combined in the single species $P$. buccae ${ }^{24}$ In a previous study,${ }^{12}$ we found that $P$. buccae ATCC 33574 and $B$. (P.) capillus ATCC 33690 were similar in all three approaches, but $B$. $(P$.) pentosaceus NP 333 and WPH 61 gave different results in GLC and enzyme tests from $P$. buccae ATCC 33574 . Results obtained by SDS-PAGE confirmed this finding; $P$. buccae and $B$. (P.) capillus gave identical protein profiles, but $B$. $(P$.) pentosaceus and $P$. buccae showed many profile differences (fig. 9). $B$. $(P$.) pentosaceus NP 333 and $B$. $(P$.) pentosaceus WPH 61 gave similar results in conventional tests and GLC, ${ }^{12}$ but they gave slightly different SDS-PAGE

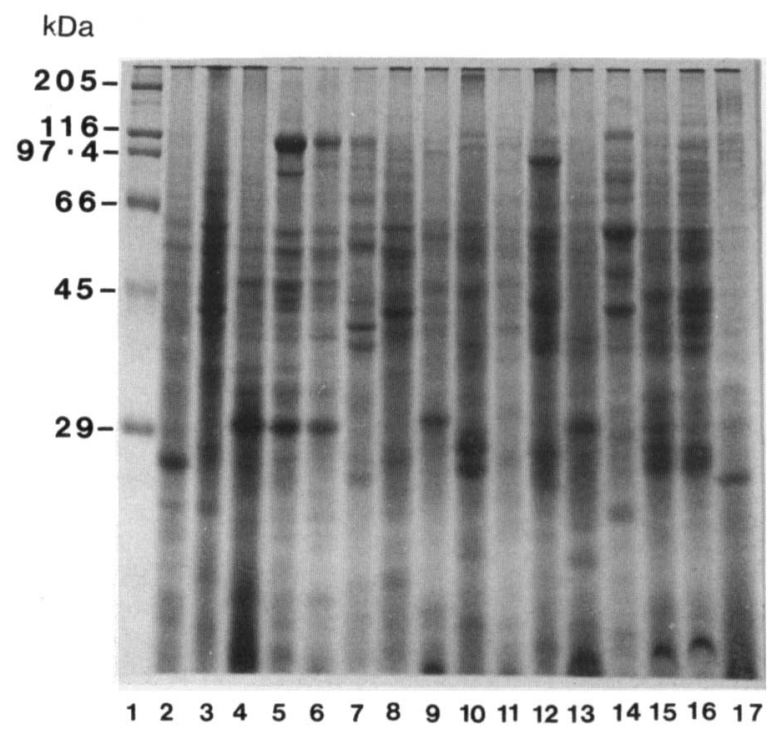

Fig. 9. SDS-PAGE protein profiles of collection strains. Track 1, high mol. wt markers; 2 and 3, P. oris ATCC 33573 and 86-20IDD; 4 and 5, $P$. buccae 83-617 and ATCC 33574; 6, B. (P.) capillus ATCC $33690 ; 7$ and $8, B$. (P.) pentosaceus NP 333 and WPH $61 ; 9$, $P$. oralis NCTC $11459 ; 10$ and $11, P$. veroralis ATCC 33779 and 83-457F; 12, P. zoogleoformans ATCC 33285; 13, P. buccalis ATCC $35310 ; 14$, P. oulora NCTC $11871 ; 15$ and 16, P. bivia VPI 6822 and VPI $5540 ; 17, P$. disiens NCTC 11157. 
profiles (fig. 9). Protein profiles of P. buccae (subgroup Ia) ATCC 33574 and P. buccae (subgroup Ib) 83-617 appeared to be identical except for the absence of a major protein band in the region $c .116 \mathrm{kDa}$.

Of the six isolates (group II) initially identified as $P$. zoogleoformans in conventional biochemical tests, ${ }^{12}$ only two gave GLC patterns identical with those of the reference strain $(P$. zoogleoformans). The four remaining isolates showed GLC and enzyme patterns different from $P$. zoogleoformans. SDS-PAGE confirmed this division; two isolates (subgroup Ila) gave electrophoretic patterns similar to $P$. zoogleoformans, but four isolates (subgroup IIb) showed many differences in their profiles. Therefore, these four isolates remained in an undesignated SDS-PAGE group (fig. 2).

Clinical isolates that were identified as $P$. oris (group III) differed slightly from the reference strain $(P$. oris ATCC 33573); common bands were seen, but there were also easily recognisable differences. Although clinical isolates of $P$. oralis (group IV) showed some variations in biochemical tests, they displayed homogeneous electrophoretic patterns. The strains of $P$.

\section{References}

1. Duerden BI. The isolation and identification of Bacteroides spp. from the normal human gingival flora. J Med Microbiol 1980; 13: 89-101.

2. Shah HN, Collins MD. Prevotella, a new genus to include Bacteroides melaninogenicus and related species formerly classified in the genus Bacteroides. Int J Syst Bacteriol $1990 ; 40: 205-208$.

3. Duerden BI, Goodwin L, O'Neil TCA. Identification of Bacteroides species from adult periodontal disease. $J$ Med Microbiol 1987; 24: 133-137.

4. Haapasalo M. The genus Bacteroides in human dental root canal infections. Taxonomic, ultrastructural and clinical studies. Proc Finn Dent Soc 1986; 82 Suppl XI-XIII : 1-87.

5. Holdeman LV, Johnson JL. Bacteroides disiens sp. nov. and Bacteroides bivius sp. nov. from human clinical infections. Int J Syst Bacteriol 1977; 27 : 337-345.

6. Brusis $T$, Luckhaupt $H$. Anaerobier infektionen bei exulzerierten Tumoren im Kopf-Hals-Bereich. Ein Beitrag zum Foetorproblem. Laryngol Rhinol Otol 1986; 65: 65-68.

7. Brook I. Direct and indirect pathogenicity of anaerobic bacteria in respiratory tract infections in children. Adv Pediatr $1987 ; 34: 357-377$.

8. Shah HN, Collins MD. Proposal to restrict the genus Bacteroides (Castellani and Chalmers) to Bacteroides fragilis and closely related species. Int J Syst Bacteriol 1989; 39 : 85-87.

9. Storm A, Dyer JK, Marsh C, Tribble JK. Identification and characterisation of species of the family Bacteroidaceae by polyacrylamide gel electrophoresis. J Dent Res 1976; 55: 252-256.

10. Moore WEC, Hash DE, Holdeman LV, Cato EP. Polyacrylamide slab gel electrophoresis of soluble proteins for studies of bacterial floras. Appl Environ Microbiol 1980; 39: 900-907.

11. Holbrook WP, Ogston SA, Ross PW. A method for the isolation of Bacteroides melaninogenicus from the human mouth. J Med Microbiol 1978; 11: 203-207.

12. Yousefi-Mashouf R, Duerden BI. An identification scheme for oral non-pigmented Prevotella (Bacteroides) species. Microbial Ecol Health Dis (in press). veroralis (group V), formed an electrophoretically and biochemically heterogeneous collection of strains (subgroups $\mathrm{Va}-\mathrm{e}$ ) despite their similarity in GLC and enzyme patterns. $P$. oulora (group VII) gave a unique protein profile and differed from other non-pigmented species by several major protein bands. The single strain that was biochemically similar to $P$. oulora showed many differences in protein profile from the reference strain.

For the majority of isolates, SDS-PAGE protein profiles enabled good differentiation and characterisation of non-pigmented species of the genus Prevotella. SDS-PAGE revealed two previously unrecognised centres of variation within the group, and indicated some heterogeneity of isolates identified as $P$. veroralis and $P$. buccae. Previous DNA hybridisation work indicating that $B$. $(P$.) capillus and $P$. buccae were synonymous ${ }^{24}$ was supported by the SDSPAGE results in this study. By contrast the contention that $B$. $(P$.) pentosaceus and $P$. buccae are synonymous, made in the same paper, ${ }^{24}$ was not supported; these two species showed many differences in SDS-PAGE profiles and in conventional test reaction patterns.

13. Rotimi VO, Faulkner J, Duerden BI. Rapid methods for identification of clinical isolates of gram-negative anaerobic bacilli. Med Lab Sci 1980; 37: 331-339.

14. Casals JB, Pringle, N. Diagnostic tablets for bacterial identification. Rosco Diagnostica, Taastrop, Denmark, 1987.

15. Popovic-Uroic T, Patton CM, Nicholson MA, Kiehlbauch JA. Evaluation of the indoxyl acetate hydrolysis test for rapid differentiation of Campylobacter, Helicobacter, and Wolinella species. J Clin Microbiol 1990; 28: 2335-2339.

16. Holdeman LV, Cato EP, Moore WEC (eds). Anaerobe laboratory manual, 4th edn. Blacksburg, VA, Anaerobe Laboratory, Virginia Polytechnic Institute and State University. 1977.

17. Laemmli UK. Cleavage of structural proteins during the assembly of the head of bacteriophage T4. Nature 1970 ; 227: 680-685.

18. Watabe J, Benno Y, Mitsuoka T. Taxonomic study of Bacteroides oralis and related organisms and proposal of Bacteroides veroralis sp. nov. Int J Syst Bacteriol 1985; 33: $57-64$.

19. Shah HN, Collins MD, Watabe J, Mitsuoka T. Bacteroides oulorum sp. nov., a nonpigmented saccharolytic species from the oral cavity. Int J Syst Bacteriol 1985; 35: 193-197.

20. Shah HN, Collins MD. Bacteroides buccalis, sp. nov., Bacteroides denticola, sp. nov., Bacteroides pentosaceus, $\mathrm{sp}$. nov., new species of the genus Bacteroides from the oral cavity. Zentralbl Bakteriol Hyg Abt 1 Orig C 1981; 2: 235-241.

21. Cato EP, Kelley RW, Moore WEC, Holdeman LV. Bacteroides zoogleoformans (Weinberg, Nativelle, and Prévot 1983) corrig., comb. nov.: emended description. Int $J$ Syst Bacteriol 1982; 32: 271-274.

22. Haapasalo, M. Bacteroides buccae and related taxa in necrotic root canal infections. J Clin Microbiol 1986; 24 : 940-944.

23. Johnston BL, Edelstein MAC, Holloway EY, Finegold SM Bacteriologic and clinical study of Bacteroides oris and Bacteroides buccae. J Clin Microbiol 1987; 25: 491-493.

24. Johnson JL, Holdeman LV. Bacteroides capillus Kornman and Holt and Bacteroides pentosaceus Shah and Collins, later synonyms of Bacteroides buccae Holdeman et al. Int J Syst Bacteriol 1985; 35: 114. 